\title{
ESTADO ACTUAL DEL CONOCIMIENTO SOBRE LA EROSIÓN POR FLUJOS CONCENTRADOS EN NAVARRA
}

\author{
J. CASALÍ, R. GIMÉNEZ, L. DE SANTISTEBAN, M. A. CAMPO, \\ J. ÁLVAREZ-MOZOS, M. GOÑI y R. GASTESI
}

Universidad Pública de Navarra, E. T. S. de Ingenieros Agrónomos, Departamento de Proyectos e Ingeniería Rural, correo electrónico de contacto: jcs@unavarra.es

RESUMEN. Los estudios a nivel europeo acerca de la erosión en flujo concentrado, especialmente a nivel de cárcavas, son escasos. En España en particular, la información al respecto es aún más limitada. En el presente trabajo damos a conocer, brevemente, el estado actual del conocimiento que, sobre la erosión en flujos concentrados, se posee en Navarra. Para ello, se exponen los principales resultados y conclusiones de estudios experimentales llevados a cabo en diferentes zonas del territorio navarro a nivel de microcuenca y cuenca. Para la localización de los diferentes sitios experimentales analizados, se utiliza una zonificación preexistente del territorio según ambientes erosivos. En la zona central de Navarra y a pequeña escala, hasta una hectárea, el tipo de cultivo predominante (cereal y viña) parece ser un factor de gran importancia en los procesos erosivos. Es así que la intensidad de erosión promedio por cárcavas y surcos en viñas es de unos $2,5 \mathrm{~kg} \mathrm{~m}^{-2}$ año-1 ; es decir más del doble de los valores más permisivos de tolerancia de pérdidas de suelos. En cereales, son igualmente importantes las pérdidas de suelo, en especial por cárcavas, aunque los valores medios de pérdidas sean inferiores a los citados umbrales máximos de tolerancia. En estudios realizados a mayor escala, la compleja topografía y relieve del territorio surgen como factores altamente significativos en el control de dichos procesos. Por ejemplo, dos cuencas cerealistas, aparentemente similares entre sí, presentan no obstante marcadas diferencias en exportación de sedimentos: en una, la producción anual media es de $1.800 \mathrm{~kg} \mathrm{ha}^{-1}$ año-1, mientras que en la otra, sólo de $300 \mathrm{~kg} \mathrm{ha}^{-1}$ año ${ }^{-1}$. En cuencas forestales, en cambio, los valores son normalmente inferiores a los registrados en cuencas cerealistas, pero a veces pueden superarlos dependiendo del manejo forestal que se haya hecho. La mayor intensidad de erosión se registra durante el invierno ya que, en esta época, los suelos se encuentran, en general, casi desnudos y con una elevada humedad. Tanto la zona central como la meridional de Navarra se ven afectadas y a veces seriamente, por erosión en cárcavas permanentes. Concretamente, dentro de Bardenas Reales de Navarra, la intensidad promedio de avance de cabecera de 
cárcava permanente toma valores, según su diferente origen y tipología, de entre 3.000 a $94.000 \mathrm{~kg} \mathrm{ha}^{-1}$ año-1. El presente trabajo incluye, además, una amplia y crítica revisión de las actuales definiciones de los principales fenómenos involucrados en la erosión en flujos concentrados.

ABSTRACT. There are few studies at a European level on concentrated flow erosion, especially with regard to gullies. In Spain, in particular, this information is still more limited. In this work, we have made a brief review of the current state of the knowledge on erosion in concentrated flows available in Navarre. For this purpose, the main results and conclusions of experimental studies carried out in different areas of the Navarre region in mini-basins and basins are presented.To locate the different experimental sites analysed, a pre-existent zone division of the territory, according to its erosive ambients, was used. In the central zone of Navarre and on a small scale, up to one hectare, the type of crop predominating (cereal and vines) seems to be a leading factor in erosion processes. So much so that the average erosion intensity per gullies and rills in vines is of around $2.5 \mathrm{~kg}$ $m^{-2}$ year $^{-1}$, that is, over double the most permissive values of soil loss tolerance. There are similarly important soil losses in cereals, especially from gullies, although the average loss values are below the tolerance threshold. In studies made on a larger scale, the complex topography and relief of the territory become highly significant factors in the control of these processes. For instance, two cerealist basins, apparently similar to each other, nevertheless show notable differences in sediment exportation: in one, the average annual production is of $1,800 \mathrm{~kg} \mathrm{ha}^{-1}$ year-1, whereas in the other it is only $300 \mathrm{~kg} \mathrm{ha}^{-1}$ year-1. In forested basins, however, the values are normally lower than those recorded in cerealist basins but they can sometimes exceed them, depending on the forest management carried out. The greatest erosion intensity is recorded during the winter since this is when, generally, the soils are almost bare and humid. Both the central and southern regions of Navarre are affected, sometimes seriously, by erosion in permanent gullies. To be specific, within Bardenas Reales de Navarra, the average intensity of the permanent gully head advance takes on values, depending on its different origin and typology, of between 3,000 to 94,000 $\mathrm{kg} \mathrm{ha}^{-1}$ year1. This paper also includes an extensive and critical review of the current definitions of the main phenomena involved in concentrated flow erosion.

Palabras clave: erosión de suelos, erosión por cárcavas, erosión por surcos, flujos concentrados, producción de sedimentos, Navarra, ambientes erosivos, cuencas experimentales, región mediterránea.

Key words: soil erosion, gully erosion, rill erosion, concentrated flow, sediment yield, Navarre, erosive ambients, experimental basin, Mediterranean region.

Enviado el 15 de Septiembre de 2008 Aceptado el 3 de diciembre de 2008 


\section{Introducción}

Las formas clásicas de erosión hídrica son por flujo no concentrado o laminar y por flujo concentrado, reconociéndose en esta última a la erosión por surcos y por cárcavas (Hutchinson y Pritchard, 1976); se distinguen, además, las cárcavas permanentes de las efímeras (Casalí et al., 1999; Nachtergaele y Poesen, 1999; De Santisteban et al., 2006; Poesen et al., 2006). Por otro lado, se destaca la erosión por túnel, originada también por la acción de un flujo concentrado, pero a nivel sub-superficial (Dunne, 1990; Faulkner, 2006; Wilson et al., 2008; Desir y Marín, 2007; Echeverría et al., 2007; Howard, 2008).

Se entiende por erosión laminar a la pérdida uniforme de finas capas de suelo debido a la acción de un flujo homogéneamente distribuido sobre el terreno (Hillel, 1998). Por sus características, este tipo de erosión es a menudo imperceptible, aunque se hayan registrado intensidades de pérdidas cercanas a las $49.000 \mathrm{~kg} \mathrm{ha}^{-1}$ año $^{-1}$ (Foster, 1986). No obstante, la erosión de tipo laminar es más una idealización que una realidad. Precisamente, los procesos de erosión raramente ocurren uniformemente sobre el terreno afectado. De hecho, el flujo erosivo, en su camino pendiente abajo, tiende rápidamente a concentrarse en canales o surcos, aunque normalmente poco manifiestos en sus orígenes.

La erosión por surcos se produce en forma de numerosos canales de pocos centímetros de profundidad, distribuidos uniformemente y al azar sobre terrenos en pendiente (Soil Science Society of America, 2001) y que pueden ser fácilmente obliterados por el laboreo convencional (Hutchinson y Pritchard, 1976). La erosión por surcos se da principalmente en suelos agrícolas, de ahí que también es frecuente que, en lugar de desarrollarse siguiendo un patrón dendrítico y, como se acaba de mencionar, aleatorio, lo hagan en cambio siguiendo las marcas en el terreno dejadas por el laboreo. En este último caso, los surcos se desarrollan en forma más o menos paralela, uniformemente espaciados y desconectados entre sí (Foster, 1986). Este espaciado regular ocurre principalmente en surcos formados sobre materiales homogéneos (e.g., Schumm, 1956). Los surcos de erosión pueden, al incrementar su tamaño, dar lugar eventualmente, a la formación de cárcavas (permanentes).

Las cárcavas permanentes son canales de erosión demasiado grandes (de entre 0,5 a 25-30 m de profundidad) para ser eliminados por el laboreo convencional (Soil Science Society of America, 2001), de ahí su carácter permanente. Las cárcavas permanentes suelen desarrollarse siguiendo un diseño dendriforme a lo largo de cursos naturales de agua (Foster, 1986). Con respecto a las cárcavas efímeras, generalmente intermedias en tamaño entre un surco y una cárcava permanente, comienzan a reconocerse como una clase particular de erosión por flujo concentrado recientemente, a partir de la década del 80, del pasado siglo. En esa época, científicos norteamericanos advierten que al considerarse sólo la erosión por surcos y cárcavas permanentes, un importante proceso y fuente de sedimento estaba siendo obviado (Foster, 1986; Gordon et al., 2007). Las cárcavas efímeras, generalmente también de trazado dendrítico, son, al igual que los surcos, lo suficientemente pequeñas como para poder ser eliminadas por el laboreo convencional (Soil Science Society of America, 2001), de ahí su calificación de efímeras. Pero, al vol- 
ver a formarse, y contrariamente a lo observado en surcos, lo hacen siempre en el mismo lugar. Sin embargo, Poesen et al. (2003), observaron cárcavas efímeras siguiendo marcas lineales del terreno, tal como suele ocurrir en surcos (ver arriba). Hasta aquí, la diferencia entre cárcava efímera y surco es poco precisa. La principal diferencia entre ambos tipos de canales suele establecerse a través del menor tamaño de los surcos. Es así que, basándose en trabajos de Hauge (1977), Poesen et al. (1993) establecen como umbral de separación una sección transversal crítica de $929 \mathrm{~cm}^{2}$. Otros proponen como umbrales críticos un ancho y profundidad mínimos de 0,3 m y 0,6 m, respectivamente (Brice, 1966); o bien sólo una profundidad mínima de 0,5 m (Imenson y Kwaad, 1980). Una distinción más precisa entre surco y cárcava efímera que prescinde del uso de valores morfológicos arbitrarios, establece que las cárcavas efímeras se forman en la vaguada que configura la confluencia de dos laderas opuestas, mientras que los surcos ocurren enteramente sobre una única ladera (Casalí et al., 1999). Esto condice con el carácter aleatorio y variable, de un episodio de lluvia a otro, con que los surcos se localizan en una misma ladera pues su formación va a estar supeditada a la alta variabilidad espacial de factores intrínsecos del suelo (estabilidad estructural, conductividad hidráulica, etc.) como del laboreo. Por otro lado, y por el contrario, la ubicación sobre el terreno de una cárcava efímera va a depender principalmente de factores topográficos que dirigen la trayectoria de la escorrentía, dando lugar a la formación de este tipo de cárcava en los lugares previstos.

No obstante, la distinción entre surcos y cárcavas efímeras sería todavía imprecisa frente a la ya mencionada situación en que ambos tipos de canales de erosión se formaran siguiendo marcas en el terreno de carácter antrópico. En este caso hipotético, la diferenciación tendría que hacerse por tamaño a través del uso de umbrales morfológicos arbitrarios (ver arriba). Sin embargo, estudios recientes hacen pensar que podría existir una diferencia funcional entre surco y cárcava efímera (Giménez y Govers, 2001; Giménez et al., 2004; Govers et al., 2007). En un surco, su flujo somero hace que se produzca una gran interacción entre dicha corriente y la (macro)-rugosidad de su cauce. Esta interrelación, en definitiva, sería la responsable de que el comportamiento hidráulico de un surco de erosión difiera notablemente del observado en un río o un canal de grandes dimensiones. En un surco, por ejemplo, la velocidad promedio del flujo se puede estimar independientemente del grado de la pendiente (Govers, 1992; Takken et al., 1998; Giménez y Govers, 2001). Se plantea entonces el siguiente interrogante: ¿Sería posible establecer un umbral hidráulico en lugar de morfológico para separar surcos de cárcavas (efímeras)? Creemos que sí. Pero la implementación de dicho umbral es todavía incierta.

La erosión por flujo concentrado puede generar importantes daños en suelos agrícolas tanto en forma directa, por su potente acción erosiva, como también indirectamente al facilitar la evacuación de sedimentos generados por la erosión por salpicadura y por flujo no concentrado. Esto último es así pues los canales de erosión pueden incrementar la conectividad en el transporte de materiales (Poesen and Hooke, 1997; Poesen et al., 2003) facilitando de este modo la transferencia y pérdida de los mismos. Sin embargo, el impacto ambiental de este tipo de fenómeno no se limita a la disminución de la capacidad productiva del suelo y de transitabilidad de los terrenos afectados, sino 
también al efecto a distancia provocado por la posterior deposición del material erosionado. Ciertamente, los quebrantos económicos causados por la colmatación y/o polución de lagos, ríos y represas muchas veces superan a los producidos en el terreno.

Por lo expuesto, no es de extrañar que la gravedad de la erosión por cárcavas tenga trascendencia mundial (De Santisteban et al., 2006), y que la erosión por cárcavas efímeras, en particular, se considere el principal problema a resolver en tierras agrícolas de Norteamérica (Alonso, 2007). Además, algunos estudios (por ejemplo, Poesen y Valentin, 2003; Poesen y Hooke, 1997) muestran que la erosión por cárcavas es un importante agente de degradación de los suelos y del ambiente en Europa (Poesen et al., 2006), especialmente en ambientes mediterráneos (Poesen et al., 2003).

Sin embargo, el estudio de la erosión por cárcavas en Europa ha estado recibiendo mucha menos atención que la proporcionada tanto a la erosión laminar como incluso a su símil, la erosión por surcos (Poesen et al., 2006). España no es la excepción en esta cuestión. De hecho, son escasos y dispersos los trabajos científicos publicados hasta la fecha en revistas internacionales sobre este importante tema (para una completa revisión sobre el tema consultar De Santisteban et al., 2006 y Solé Benet, 2006). Sin embargo, consideramos que el grado de conocimiento alcanzado en Navarra sobre la realidad regional de la erosión por flujo concentrado es, aunque todavía limitado, significativo y, de alguna manera, extrapolable a ambientes similares.

Es así que el objetivo del presente artículo es el dar a conocer, de manera sucinta, el estado actual del conocimiento sobre la erosión por flujo concentrado, especialmente a nivel de cárcavas, en territorio navarro. Para ello, presentaremos los principales resultados y conclusiones de una serie de trabajos experimentales realizados en diferentes zonas de Navarra representativas, en su conjunto, de gran parte de la geografía y medio ambiente de esta región española. Estudios previos permiten dividir el territorio de Navarra en una serie de ambientes erosivos (Donézar et al., 1990 a y b) (Fig. 1) caracterizados, cada uno, por una combinación particular de condiciones climáticas, edáficas, geológicas, topográficas y antrópicas. Se diferencian, así, 5 ambientes o zonas: Atlántica, Pirenaica, Pre-Pirenaica, Media y Ribera (Fig. 1). A continuación, usaremos esta zonificación para ubicar los sitios donde se llevaron a cabo los mencionados trabajos experimentales.

\section{Erosión por flujos concentrados en Navarra}

\section{Zona Media}

En este ambiente el paisaje es abierto y rodeado de montes de poca altitud (Donézar et al., 1990 a y b). El clima es del tipo Mediterráneo Continental. A medida que nos desplazamos hacia el sur, las temperaturas se incrementan, mientras que las precipitaciones, por el contrario, decrecen; de ahí que el sur presente un ambiente semiárido. Son frecuentes las precipitaciones de alta intensidad y/o duración que conllevan un alto poder erosivo. No obstante, la erosividad de las lluvias se encuentra, en general, por debajo de 


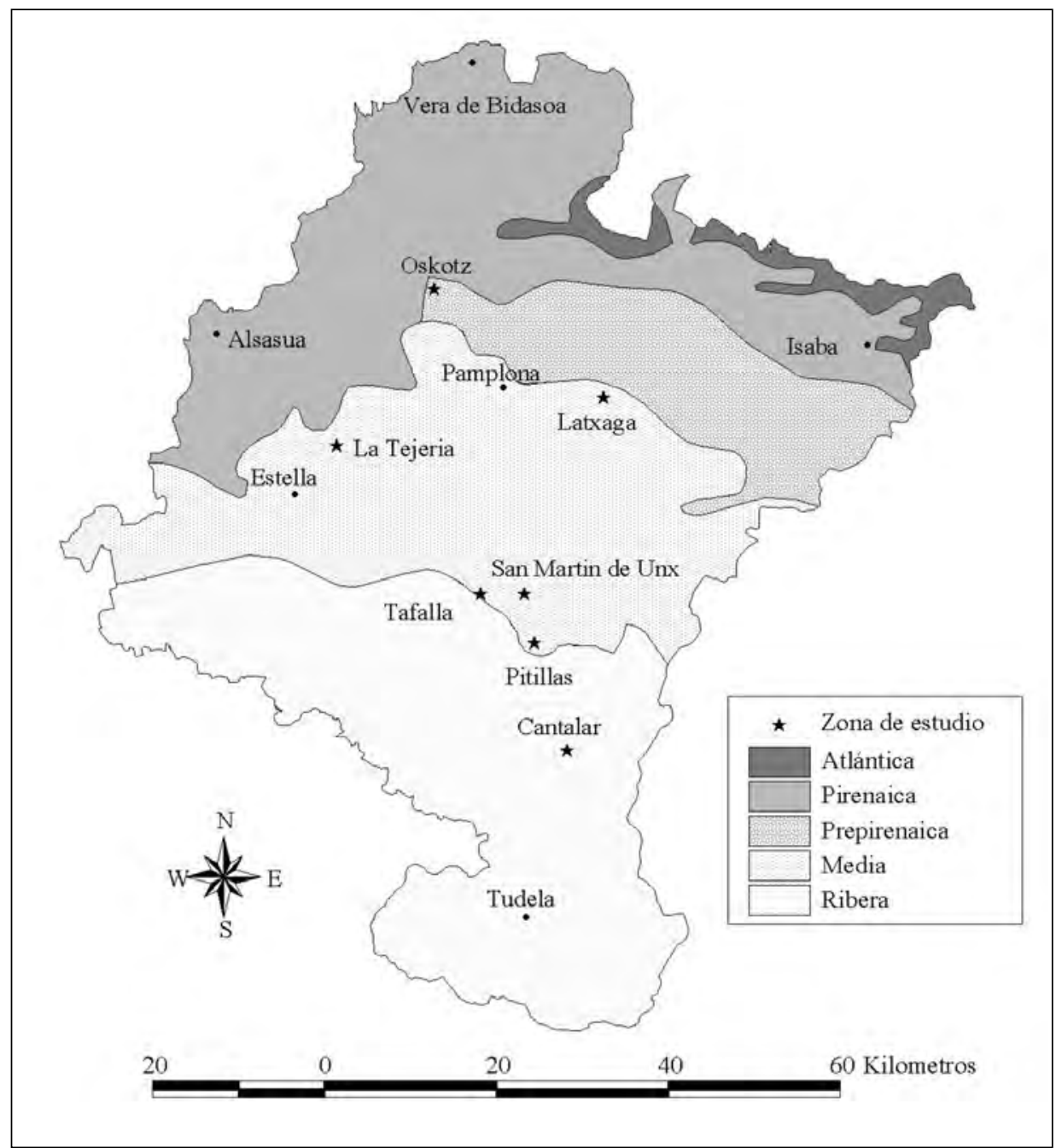

Figura 1. Mapa de ambientes erosivos en Navarra (Donézar et al., 1990ab) con localización aproximada de los sitios experimentales mencionados en el texto

los valores medios registrados en toda España (ICONA, 1988). Son usuales los suelos vulnerables a la erosión por su alto contenido de limo y/o sodio de intercambio. Los principales cultivos de la zona son los cereales de invierno y la vid, los cuales ocupan, a su vez, más del 25\% del área productiva de Navarra (Gobierno de Navarra, 2004). Los cereales se siembran a comienzos de octubre luego de preparar la cama de siembra mediante laboreo, aunque es frecuente dejar el suelo en barbecho cada año por medio. Por su parte, la vid, cultivo permanente y poco competitivo con las malezas, requiere de un frecuente laboreo a lo largo del año para eliminar del terreno la vegetación indeseable. 
Una detallada medición de las pérdidas de suelo debidas a erosión por flujo concentrado, y discriminadas entre las categorías de surcos y cárcavas efímeras, fue llevada a cabo en diversas microcuencas agrícolas de entre 1.300 a $16.000 \mathrm{~m}^{2}$, cada una. Estas pequeñas cuencas, ocupadas en su momento con cereales o viñedos, se extienden en un área que comprende los municipios navarros de Pitillas, Tafalla y San Martín de Unx (Fig. 1). En esta zona en concreto se registra una temperatura anual promedio de aproximadamente $13^{\circ}$ y una precipitación media anual de 500-600 mm (Elías y Ruíz, 1986). Los suelos predominantes pertenecen a la Facies Ujué que en Navarra ocupan un área de aproximadamente $620 \mathrm{~km}^{2}$ (Gobierno de Navarra, 1977). En la mayoría de estos sitios experimentales, los estudios se realizaron durante 6 años consecutivos (Casalí et al., 1999), mientras que en los sitios restantes, durante un par de años (De Santisteban et al., 2006). La medición de los canales de erosión se efectuó, básicamente, con la ayuda de un perfilómetro de agujas (Fig. 2) (Sancho et al., 1991; Smith, 1993; Casalí et al., 1999; Casalí et al., 2006), gracias al cual se pudo calcular el área de distintas secciones transversales al eje longitudinal de cada canal. Este dato, junto a la longitud de las diferentes secciones de cauce, permitió una detallada cubicación de las cárcavas y surcos.

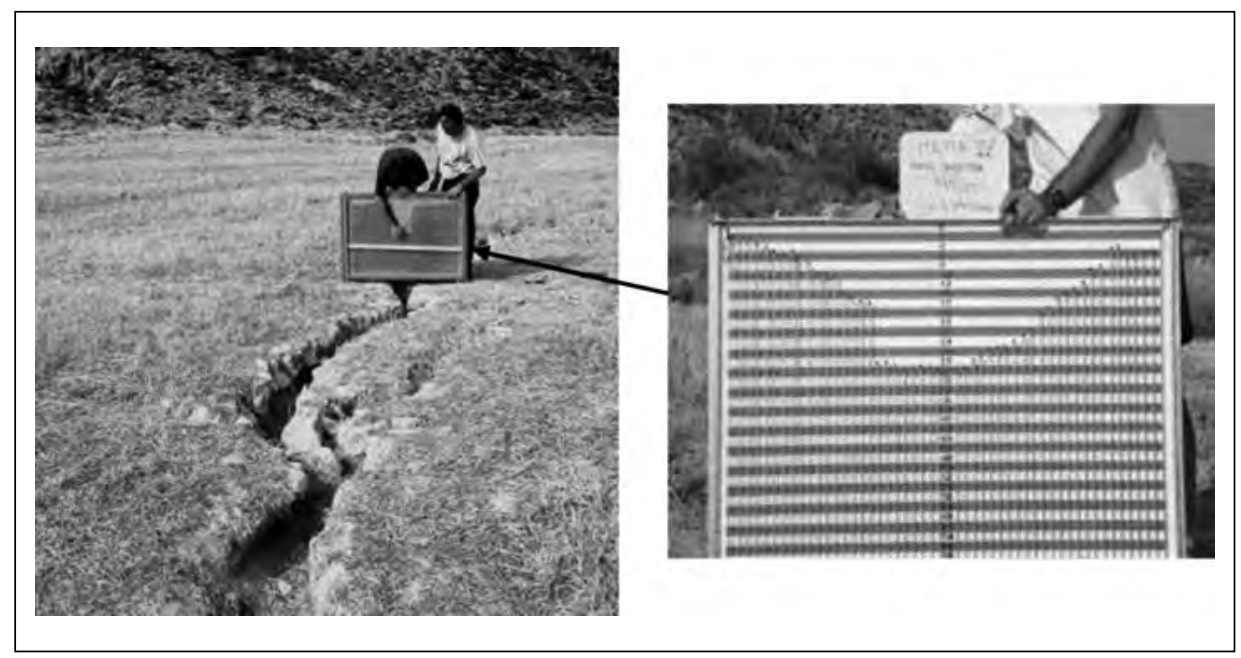

Figura 2. Medición de la sección transversal de una cárcava mediante el uso de un perfilomómetro de aguja

Si aceptamos o toleramos pérdidas de suelo de no más de $1,12 \mathrm{~kg} \mathrm{~m}^{-2}$ año-1 (Hall et al., 1985), la intensidad promedio de erosión por cárcavas en viñas es muy elevada: duplica el mencionado umbral (Fig. 3). Sin embargo, no debemos subestimar el carácter atípico, estadísticamente hablando, de ciertos eventos de erosión (ver en Fig. 3, los valores ubicados más allá de los bigotes del diagrama de caja), ya que los mismos están de alguna manera reflejando, justamente, el carácter aleatorio, tanto en el tiempo como en el espacio, con que los fenómenos erosivos suelen manifestarse. Precisamente, la aleatoriedad de estos fenómenos se corresponde con la alta fluctuación e impredecible ocu- 


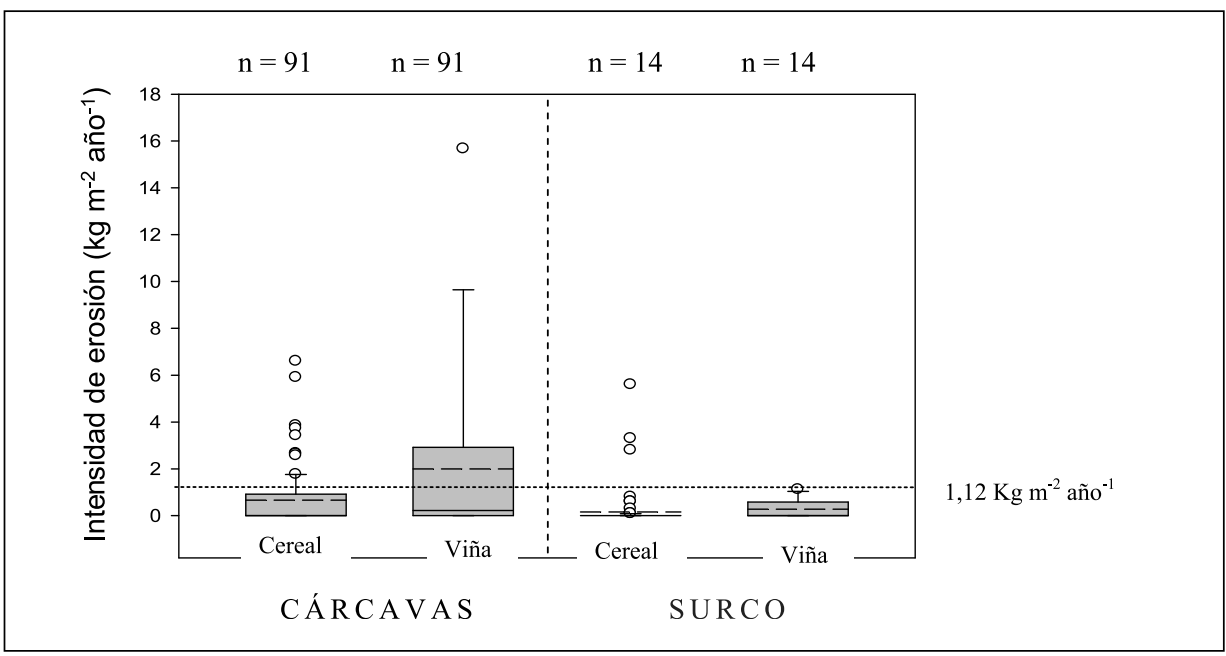

Figura 3. Diagrama de caja de la intensidad de erosión por cárcavas y surcos determinada en microcuencas con cereales y viñas. Los límites inferior y superior de la caja indican los percentiles 25 y 90, respectivamente; los bigotes indican los percentiles 10 y 90 . La línea continua y la línea discontinua indican la mediana y la media, respectivamente. Se muestra la máxima tolerancia a pérdida de suelo (Hall et al., 1985)

rrencia de las lluvias erosivas; características estas últimas del clima mediterráneo (Ramos y Martínez-Casasnovas, 2004). Dicho esto, debemos considerar igualmente importantes las pérdidas de suelo (en especial las debidas a cárcavas) observadas en cereales, aunque sus valores medios sean inferiores al umbral de tolerancia (Fig. 3).

En realidad, las mencionadas pérdidas anuales de suelos en viñas y cereales serían aún más significativas si reconocemos, primero, que el umbral de tolerancia utilizado como referencia (ver arriba) es elevado cuando se aplica a suelos someros, como son los nuestros. Segundo, las pérdidas de suelo que se indican son sólo las debidas a la erosión por flujos concentrados. No se considera ni la erosión laminar, ni la cantidad de sedimentos que esta última añade a los surcos y cárcavas. Precisamente, estos sedimentos añadidos al flujo concentrado no modifican la morfología de los canales de erosión al ser totalmente evacuados por dicho flujo.

Cabe mencionar que valores de intensidad de erosión hídrica total en viñedos ubicados en la misma zona de estudio que nos ocupa (Casalí et al., 2009), concuerdan con los arriba mencionados. En efecto, a partir de 20-25 años desde la fecha de plantación, estos viñedos registran una intensidad de erosión total de aproximadamente $2,5 \mathrm{~kg} \mathrm{~m}^{-2}$ año $^{-1}$ (Casalí et al., 2009). Este último valor es muy cercano a la suma de los valores promedios de erosión en cárcavas y surcos registrados en viñas (ver Fig. 3).

Podemos concluir que, en la región estudiada, un factor altamente condicionante de la erosión hídrica, es el uso de la tierra. El mayor laboreo a lo largo del año exigido por 
los viñedos (ver arriba) trae como consecuencia que sus suelos permanezcan desnudos y, consecuentemente más vulnerables a la acción de los agentes erosivos que aquellos suelos bajo cultivo de cereales.

Es indudable que el mejor entendimiento de los (sub)-procesos y factores que dan lugar a la formación de cárcavas es primordial a la hora de modelizar dicho fenómeno erosivo. Por ello, resulta oportuno destacar que se identificaron en la zona, según su diferente origen, 3 tipos de cárcavas efímeras, a saber: clásicas, de drenaje y asociadas a discontinuidad (Casalí et al., 1999) (Fig. 4). Las cárcavas efímeras clásicas se originan a partir de la escorrentía procedente de la misma parcela donde se localiza dicha cárcava. Responden al concepto ortodoxo de cárcava efímera, de ahí su apelativo de clásica. En una cárcava efímera de drenaje, en cambio, la escorrentía que la genera proviene, principalmente, de una parcela no agrícola, de límites a veces poco definidos, ubicada aguas arriba de la parcela cultivada donde se forma la cárcava en cuestión. Esta parcela no agrícola debe su carácter de tal al hecho de presentar, generalmente, un terreno muy empinado y/o un suelo demasiado somero para su aprovechamiento agrícola. Por último, las cárcavas efímeras asociadas a discontinuidad se desarrollan a raíz de un brusco quiebre en el terreno, a modo de un escalón; de ahí la denominación asociada a discontinuidad. Sobre este escalón el flujo caerá en forma de cascada, favoreciendo así la formación de una cárcava, aguas abajo. Estos bruscos quiebres del terreno pueden producirse, por ejemplo, en los bordes de las parcelas, o en las zonas de separación entre parcelas y caminos. Por otro lado, la erosión por túnel suele acompañar la formación de este tipo de cárcava, acelerándola. Para una completa descripción de las diferencias morfológicas observadas en estos tipos de cárcavas efímeras, ver Casalí et al. (1999). Sólo bajo cereal se logró observar la formación de estos 3 tipos de cárcavas efímeras en cantidad suficiente para permitir discriminar valores de intensidad de erosión según la citada tipología (Fig. 5). Cabe aclarar que, la gran incertidumbre que se presenta al tratar de definir con rigor el área de drenaje de las cárcavas asociadas a discontinuidad, malogra el cálculo de pérdida de suelo por unidad de área, precisamente, vinculado a este tipo de cárcava; de ahí que se haya omitido en la Fig. 5. Se observa que las pérdidas de suelo debidas a cárcavas efímeras de drenaje son superiores, aunque levemente, a su semejante, las cárcavas efímeras clásicas (Fig. 5). Una posible explicación de este hecho sería la siguiente. Frente a una lluvia dada, la elevada pendiente de la parcela no agrícola (principal área de aporte de la escorrentía), junto a un suelo de escasa capacidad de captación de agua, favorecerían el aumento y velocidad del flujo de agua. Esta escorrentía, con su capacidad erosiva así potenciada, daría lugar a la formación, en la parcela cultivada, de una cárcava de drenaje de un tamaño significativamente mayor al esperado.

Uno de los principales objetivos de la modelización es el poder relacionar las pérdidas de suelo con parámetros topográficos precisos. Es así que, De Santisteban et al. (2006) establecieron, para la zona que nos ocupa, un índice empírico de pérdida de suelos por cárcavas efímeras en función de parámetros topográficos. Los valores de este índice se definen conociendo (i) la superficie de la cuenca que contiene la cárcava en cuestión y (ii) la pendiente general de dicha cuenca. Por lo tanto, gracias a esta herramienta se pueden identificar zonas propensas a este tipo particular de erosión por flujo concentrado. 

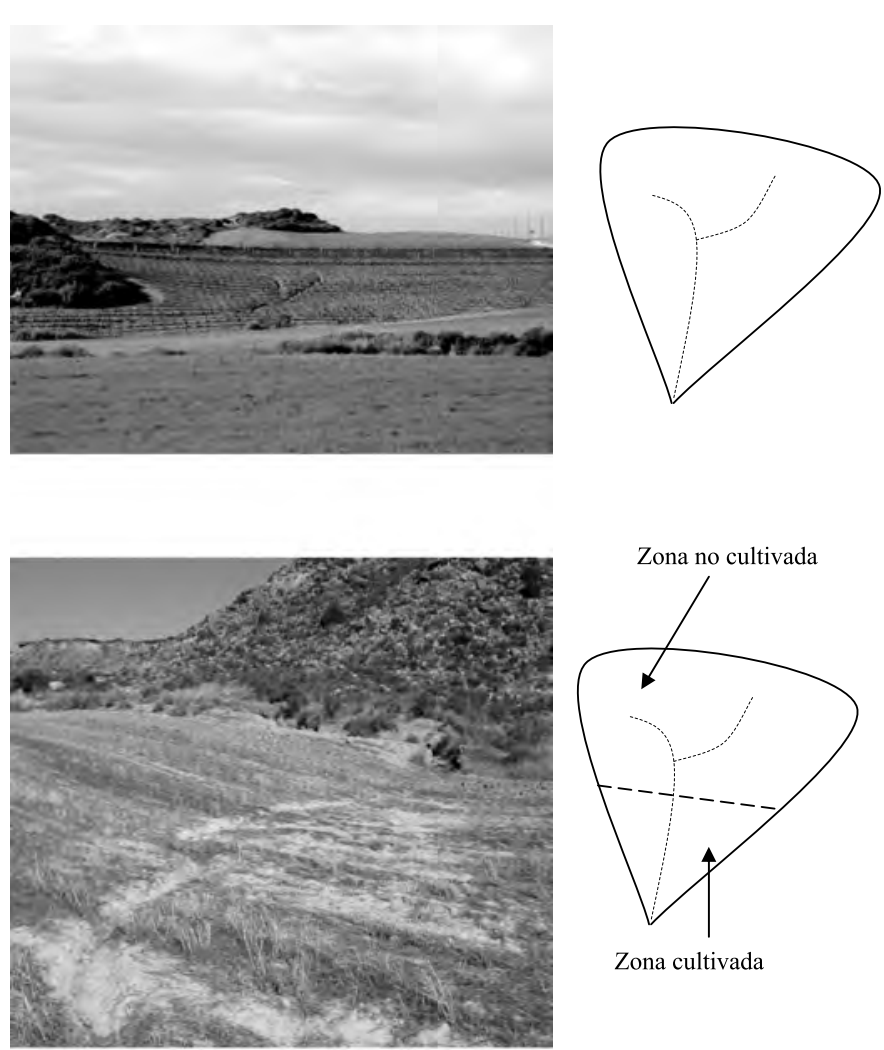

Zona cultivada

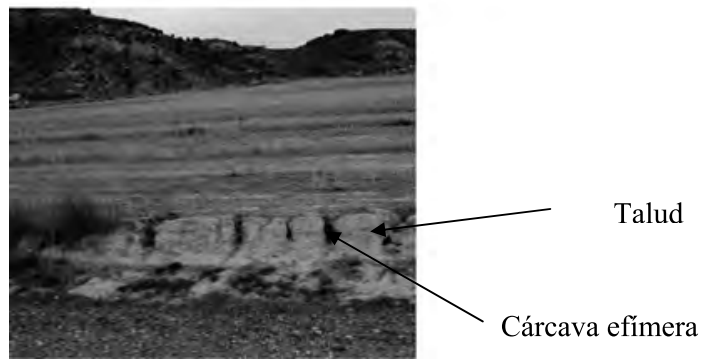

Figura 4. Arriba: Vista panorámica de una cárcava efímera clásica en una parcela cultivada con viña en la cuenca de Beramendi, Tafalla (Navarra), y esquema de una cuenca con cárcavas efímeras clásicas. La cuenca hidrográfica que vierte a la cárcava se encuentra completamente inmersa en la parcela cultivada. Centro: Vista de una cárcava efímera de drenaje en una parcela cultivada con cereal, cuenca de Camino, Pitillas (Navarra), y esquema de una cuenca con cárcavas efímeras de drenaje. La parcela cultivada afectada por cárcavas efímeras es sólo una parte de la cuenca hidrográfica, de modo que la escorrentía que irrumpe en la parcela se origina en la zona no cultivada ubicada aguas arriba. Abajo: Vista de una cárcava efímera asociada a discontinuidad 


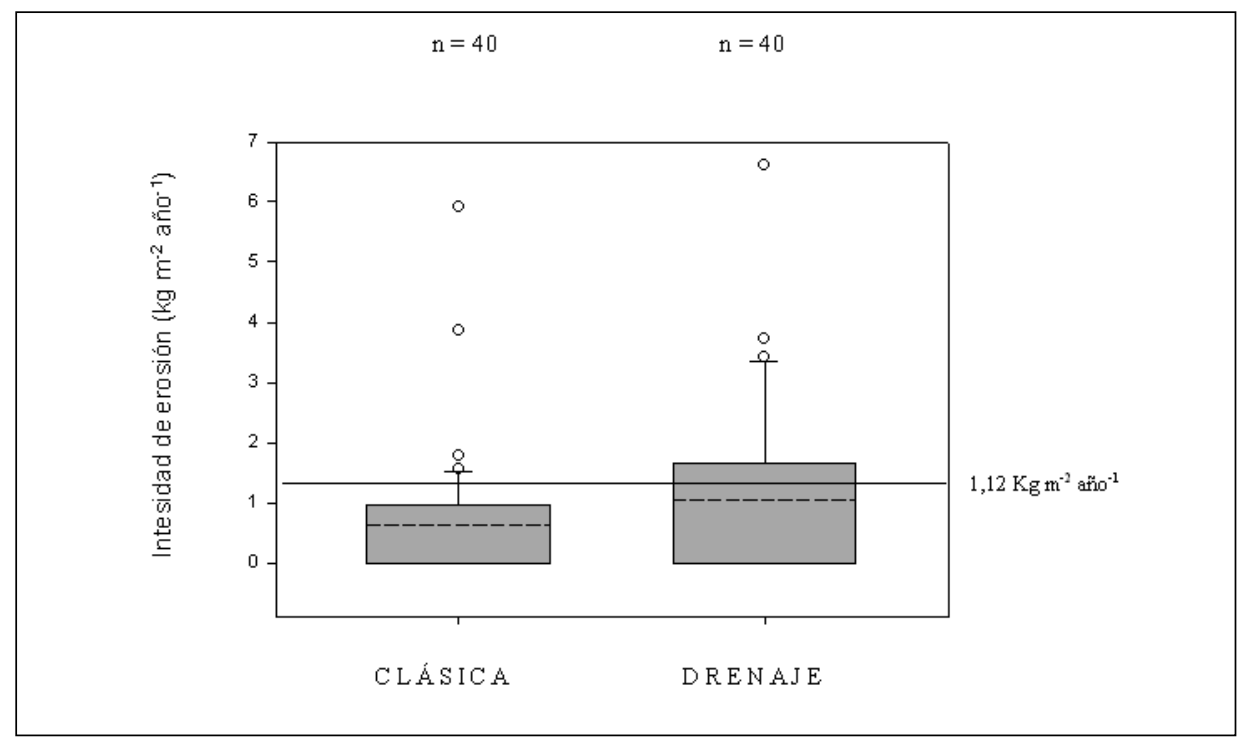

Figura 5. Diagrama de caja de la intensidad de erosión por cárcavas efímeras clásica y de drenaje registrada en microcuencas con cereales. Los límites inferior y superior de la caja indican los percentiles 25 y 90, respectivamente; los bigotes indican los percentiles 10 y 90 . La línea discontinua indica el valor promedio. Se muestra la máxima tolerancia a pérdida de suelo (Hall et al., 1985)

A continuación haremos referencia a información procedente de una red de cuencas experimentales que el Gobierno de Navarra posee y mantiene, desde hace más de una década, en distintas zonas de su jurisdicción. A través de estas cuencas se pretende evaluar el efecto meridional de la actividad agraria típica regional (Casalí et al., 2008), registrándose, por ejemplo, la cantidad de sedimentos evacuados en el tiempo a la salida de cada cuenca. Sólo la erosión hídrica total (sin discriminación de procesos) se puede inferir a través de estos registros de producción de sedimentos. Sin embargo, y gracias a observaciones y mediciones complementarias realizadas a campo por los autores, se puede conjeturar sobre la ocurrencia de erosión por cárcavas y surcos, exclusivamente.

En la zona que nos atañe, encontramos dos de estas cuencas experimentales: La Tejería, en el término municipal de Villanueva de Yerri, y Latxaga, en los términos municipales de Lizoain y Urroz-Villa (Fig. 1, Fig. 6). Una completa descripción de estas cuencas se presenta en Casalí et al. (2008). Destacamos que ambas cuencas son similares en cuanto a superficie (unas 200 ha), tipo de suelo, clima predominante y uso de la tierra (cerealista). La temperatura y precipitación media anual, para ambas cuencas, es de unos $13^{\circ}$ y $750 \mathrm{~mm}$, respectivamente. No obstante, la exportación promedio de sedimentos en 10 años (que relacionamos directamente con la intensidad de erosión del suelo) es un orden de magnitud superior en La Tejería que en Latxaga (Fig. 7) (Casalí et al., 2008). La producción de sedimentos se concentra mayoritariamente en invierno (Fig. 8). En esta 


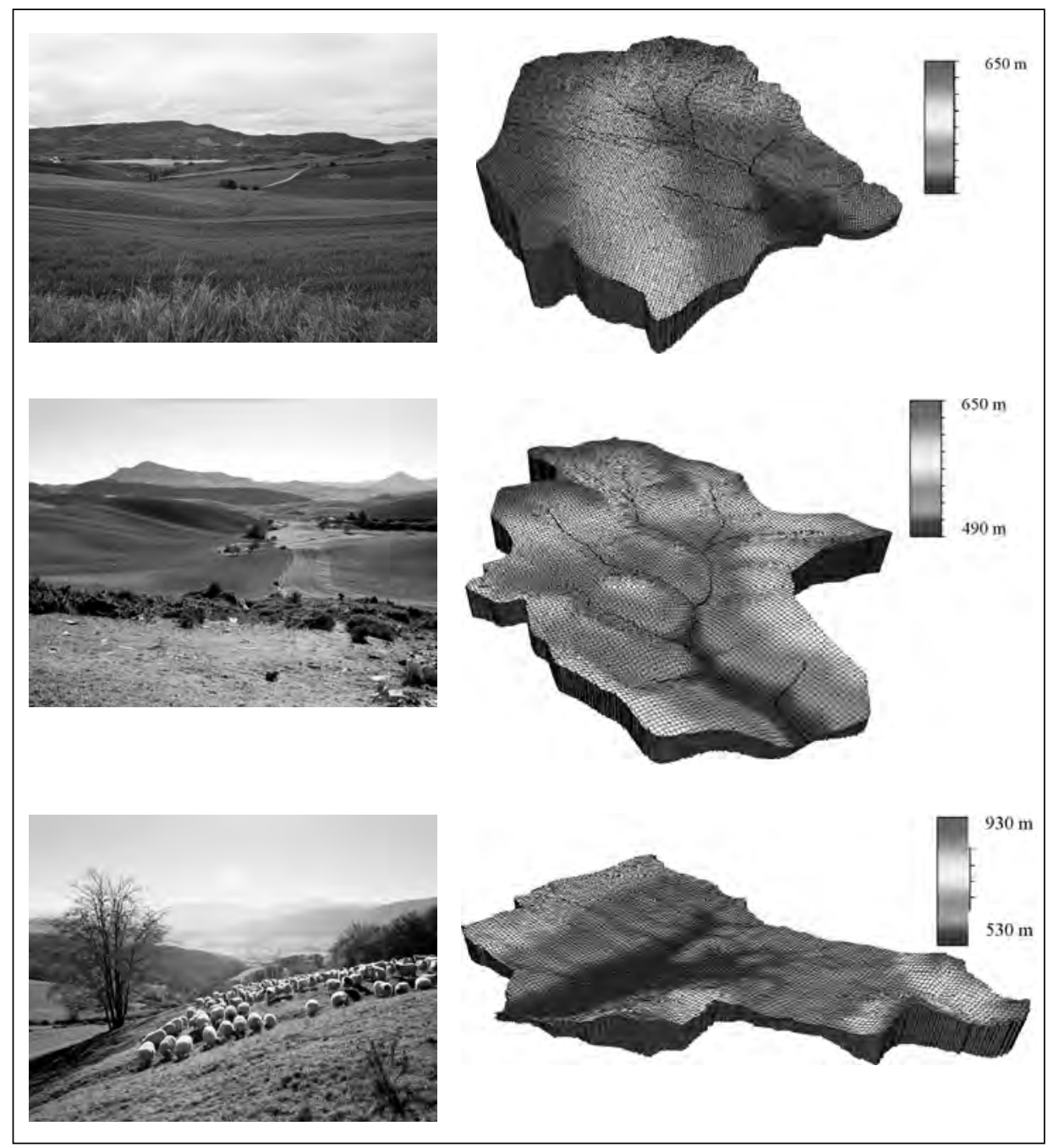

Figura 6. Vistas parciales e imágenes tridimensionales de las tres cuencas experimentales mencionadas en el texto. De arriba abajo: La Tejería, Latxaga, y Oskotz.

época del año, la generación de escorrentía se ve favorecida por el normalmente alto contenido hídrico de los suelos, casi desnudos, al momento de producirse las lluvias. Sin embargo, no es anormal que aún en verano se generen grandes cantidades de sedimentos por la ocurrencia de tormentas aisladas. Es así que se registraron valores de sedimentos exportados de hasta $5.600 \mathrm{~kg} / \mathrm{ha} / \mathrm{año}$ en la cuenca de La Tejería, mientras que en Latxaga estos valores fueron mucho más discretos. Ciertamente, las pérdidas de suelo en La Tejería eventualmente podrían superar los máximos valores de tolerancia, mientras que en Laxtaga, en cambio, estos umbrales difícilmente se alcanzarían. Ahora bien, en sub- 


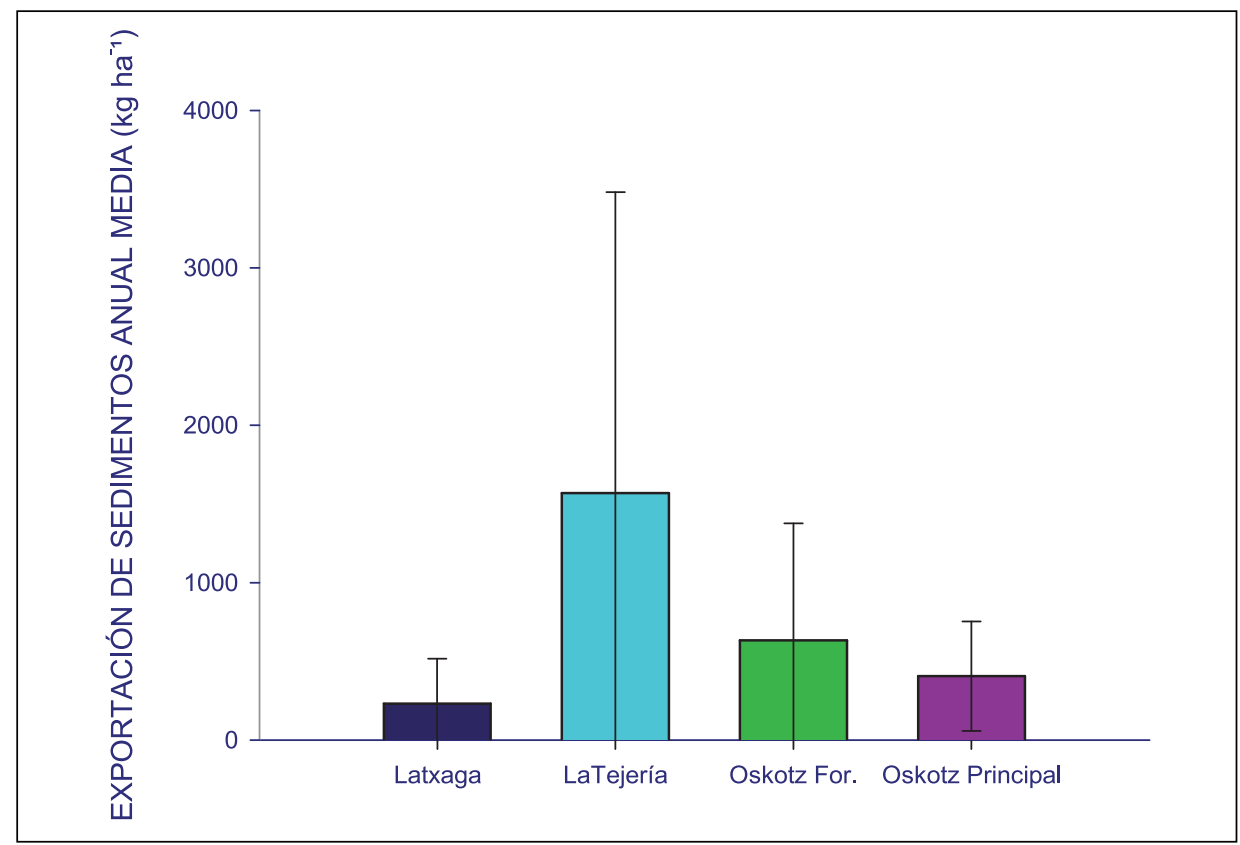

Figura 7. Valores medios anuales de exportación de sedimentos en las diferentes cuencas experimentales mencionadas en el texto

cuencas de La Tejería se han registrado importantes pérdidas de suelo asociadas a la formación de cárcavas efímeras y surcos (Casalí et al., 1999) (Fig. 9): en algunas de sus subcuencas superaron los $80.000 \mathrm{~kg} / \mathrm{ha} / \mathrm{año}$. Por el contrario, en la cuenca de Latxaga, la erosión por cárcavas efímeras y surcos parece carecer de relevancia. Por lo tanto y aunque no podemos ser concluyentes al respecto, presumimos que es la ocurrencia de la erosión en flujos concentrados, sólo presente en algunas subcuencas de La Tejería, la que marca la diferencia en la intensidad total de erosión entre ambas cuencas experimentales. Este marcado contraste en los valores de erosión podría atribuirse en parte a la diferente topografía predominante en cada una de estas cuencas y a la también distinta pendiente general del cauce principal respectivo. En efecto, los cauces de desagüe más importantes de la cuenca de La Tejería presentan una mayor pendiente general, lo cual junto a una topografía poco abrupta y una forma circular de la cuenca, facilita la generación de caudales elevados. Además, los taludes de los cauces son más vulnerables a la acción erosiva de la corriente al estar casi desprovistos de vegetación. En cambio, en la cuenca de Latxaga, la topografía es marcadamente más abrupta y la forma de la cuenca menos circular. Además, la pendiente general de los cauces es menor y éstos se encuentran cubiertos de vegetación, lo cual, a su vez, favorece la sedimentación del material arrancado de las laderas (Casalí et al., 2008). No obstante, no poseemos, en realidad, una explicación del todo evidente sobre este disímil comportamiento erosivo de las cuencas experimentales. Del análisis comparativo entre dos cuencas cerealistas resulta interesante 


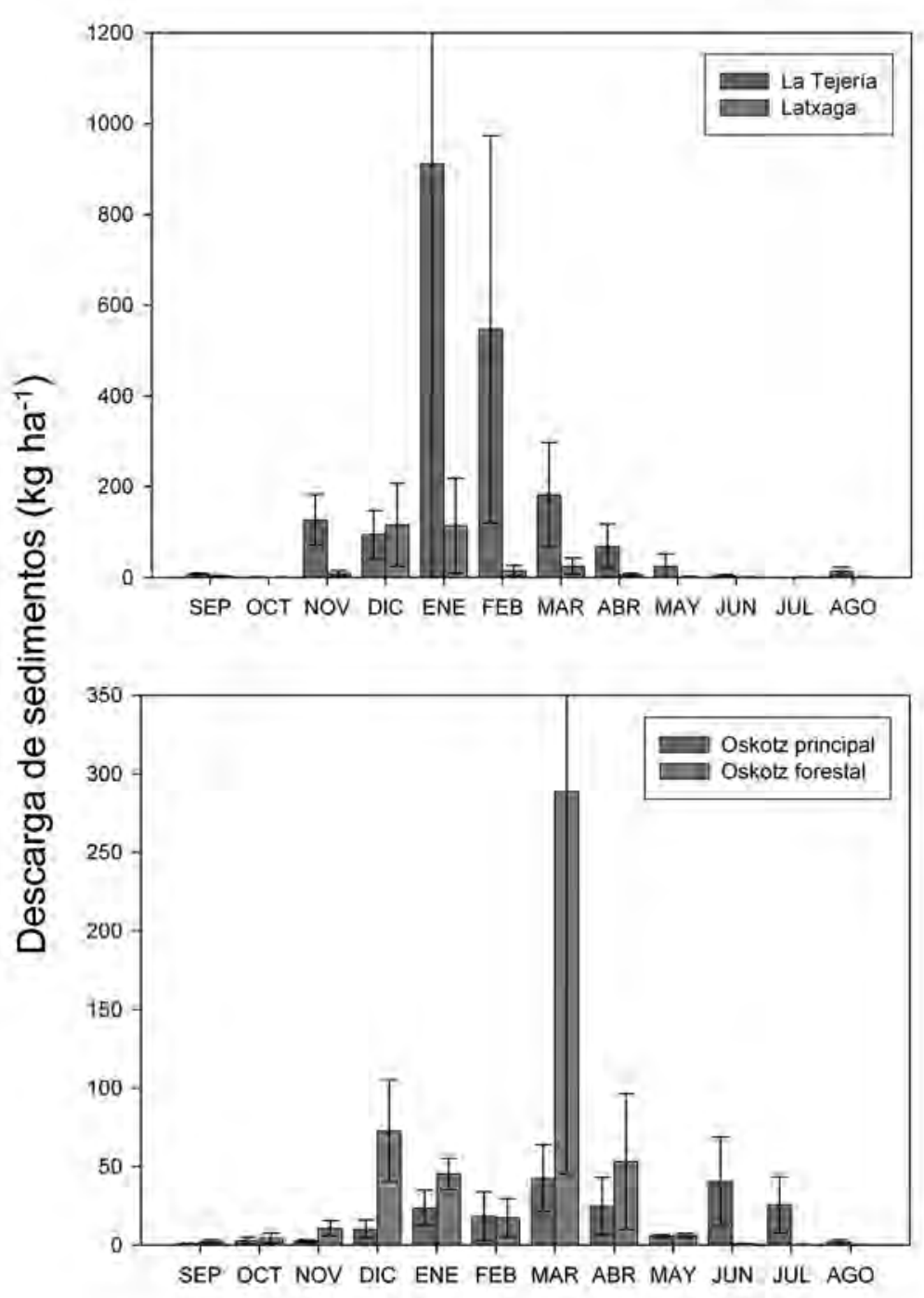

Figura 8. Valores medios mensuales de exportación de sedimentos para las diferentes cuencas experimentales mencionadas en el texto 


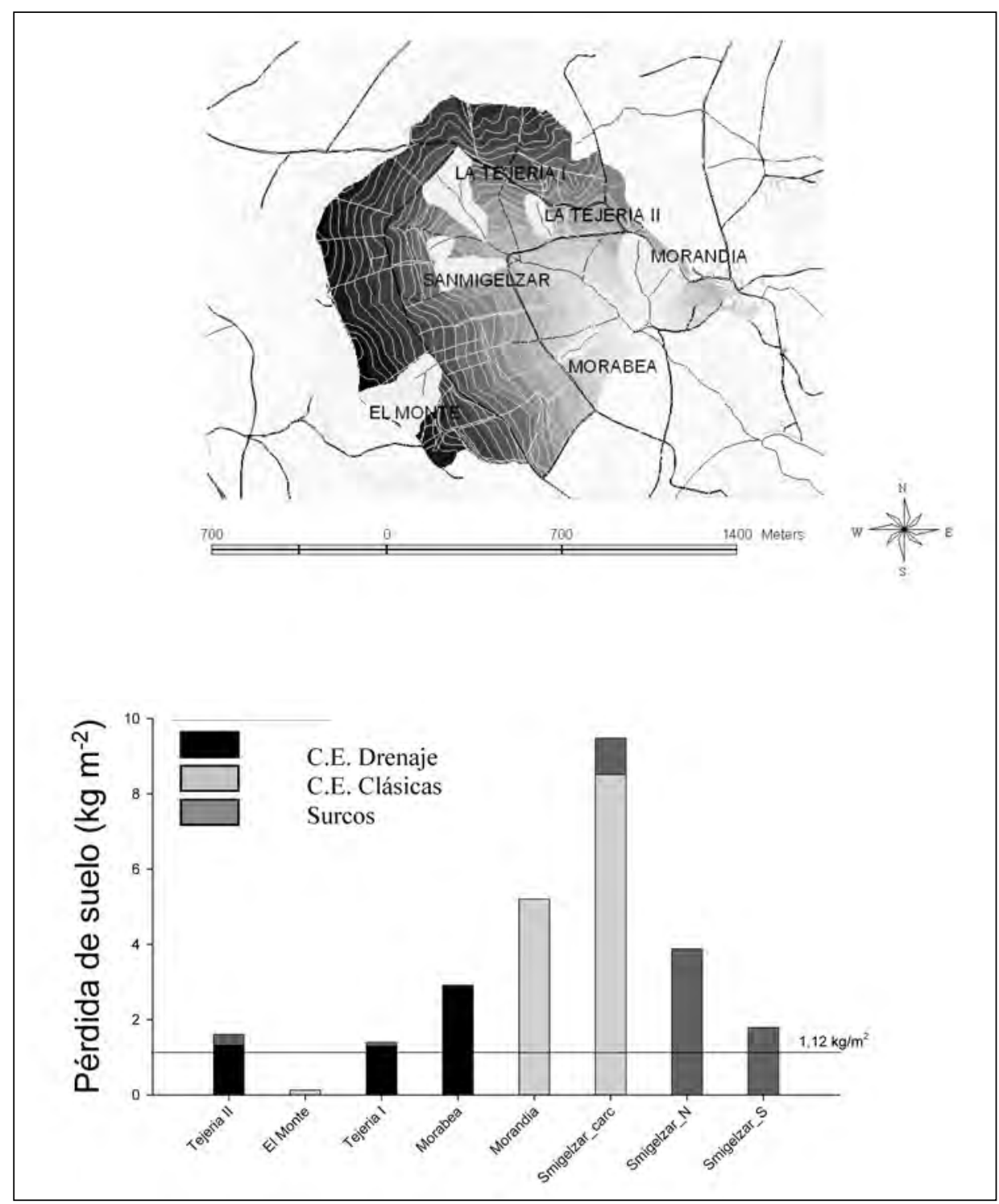

Figura 9. Pérdidas de suelo por flujo concentrado medidas a campo en diversas subcuencas de La Tejería durante el período agrícola 2003-2004. Se muestra la máxima tolerancia a pérdida de suelo (Hall et al., 1985) 
el hecho de que no es el uso de la tierra, justamente, el factor condicionante de los procesos erosivos, como sí lo es en las microcuencas experimentales, citadas con anterioridad. Es así que, cada factor controlador de la erosión se manifestará en forma particular, más o menos potenciado, según la escala en que estemos efectuando nuestras mediciones. Concretamente en nuestras cuencas, y a diferencia de las citadas microcuencas, la topografía y la morfología de las mismas parecen jugar un papel relevante como desencadenante de los procesos erosivos. Se comprueba así que la efectividad del proceso erosivo está directamente relacionada a la escala de medición utilizada (Morgan, 2005, Pág. 65).

\section{Zona Prepirenaica}

El clima de la región es del tipo Subatlántico. Los suelos son profundos en los valles y en las áreas de menor pendiente, mientras que en las zonas más empinadas son más someros. Además, se observan diferencias de espesor del suelo entre las solanas y umbrías de los accidentes montañosos (Donézar et al., 1990 a y b). Los terrenos cultivados, con predominio del cereal, se encuentran en aquellas áreas con suelos más profundos. La región se caracteriza por una gran cantidad de tierras situadas en laderas de fuerte pendiente, antiguamente cultivadas, pero en la actualidad, abandonadas en su mayor parte. Tras abandonar el cultivo, estas tierras quedan ocupadas generalmente por pastizales o monte bajo.

En esta zona Prepirenaica, al noroeste de la Comunidad Foral de Navarra, se sitúa una tercera cuenca experimental de 1.674 ha, denominada Oskotz (Fig. 1, Fig. 6). En esta zona se registra una temperatura y precipitación anual media de $11^{\circ}$ y $1.200 \mathrm{~mm}$, respectivamente. En líneas generales, la topografía de esta cuenca es similar a la arriba mencionada, Latxaga. Las pendientes en Oskotz son suaves en los fondos llanos del valle y moderadas en las laderas. Sin embargo, en ciertas laderas, las pendientes pueden llegar a ser considerablemente superiores a las de Latxaga. Los suelos predominantes son someros (menos de 0,5 m de profundidad), de clases texturales finas y, a diferencia de los suelos predominantes en las citadas cuencas cerealistas (La Tejería y Latxaga), el contenido hídrico edáfico durante la época seca es relativamente elevado, lo cual se traduce en ausencia de carbonatos en el perfil de suelo. Los suelos de mayor contenido hídrico se ubican en las laderas de acumulación. En Oskotz, dos son los usos predominantes de la tierra: más de un $60 \%$ de su superficie está ocupada por bosques con especies como el haya, roble melojo y pino, mientras que el resto está cubierto por praderas y pastizales donde se desarrolla una intensa actividad ganadera. En esta cuenca experimental existen dos estaciones hidrológicas, una que realiza mediciones de la cuenca en su conjunto (bosques y pastizales), a la que llamamos principal. Y una segunda estación que se localiza a la salida de una subcuenca ocupada casi exclusivamente por bosque a la que denominamos, precisamente, forestal (451 ha).

En la cuenca de Oskotz, la protección de los suelos contra el efecto erosivo de las lluvias, dado por la presencia de pastos o bosques, minimiza la erosión (Fig. 7). Esto es así a pesar de registrarse valores promedios de precipitación y escorrentía muy superiores a los verificados en ambas cuencas cerealistas (La Tejería y Latxaga). Sin embargo, en la 
subcuenca forestal, pueden registrarse intensidades de erosión elevadas en terrenos que quedaron desprotegidos luego de una tala o aclareo. Un ejemplo de esto último se produjo en el período 2002-2003 donde la intensidad de erosión determinada en los suelos de Ozkotz forestal superó ampliamente a la registrada aún en la cuenca experimental cerealista de Latxaga, en la misma época. Al igual que en las cuencas experimentales cerealistas analizadas, en la cuenca de Oskotz la mayor parte de la exportación de sedimentos ocurre en invierno (Fig. 8). Sin embargo, en esta cuenca se han observado también valores significativos en los meses de junio y julio, debido, probablemente, a talas selectivas que dejaron el suelo vulnerable frente a aisladas pero importantes precipitaciones. Para Oskotz no se cuenta, lamentablemente, con datos y observaciones adicionales que den pistas ciertas sobre los diferentes mecanismos y procesos erosivos predominantes en la cuenca.

\section{Zona de Ribera}

La parte más meridional de Navarra, que bordea al norte con la zona Media en suave transición, es lo que tradicional y geográficamente se denomina la Ribera. El eje principal de esta zona es el río Ebro y sus afluentes. El clima es semiárido a árido correspondiendo al tipo mediterráneo continental. Las temperaturas son altas en verano y frías en invierno: la amplitud térmica es realmente importante. Son frecuentes las lluvias torrenciales de alta erosividad. El balance hídrico es claramente desfavorable al desarrollo de los cultivos. El relieve es en general suave y ondulado, sólo interrumpido por los valles fluviales y sus terrazas.

Al Sur-Este de esta zona de Ribera se destaca una extensa depresión de cerca de 42.000 ha, denominada Bardenas Reales de Navarra. Concretamente, en esta extensa región la temperatura media anual es de $14^{\circ}$, con promedio de $5,4^{\circ}$ en el mes de enero y $24^{\circ}$ en el mes de julio. La precipitación media anual es de $400 \mathrm{~mm}$. Al norte de Bardenas Reales de Navarra se encuentra un área deprimida, de unas 25.000 ha, llamada Bardena Blanca. Esta última región es altamente erosionable, con suelos con elevado contenido de limo y sodio de intercambio. Es notable en esta zona la presencia de todo tipo de erosión hídrica: laminar, por surco, cárcavas, etc.

A continuación destacamos parte de los resultados de una serie de estudios experimentales que se están llevando a cabo en una cuenca de 300 ha, llamada el Cantalar, localizada dentro de Bardena Blanca (Campo et al., 2007). El uso de la tierra en el Cantalar es similar a la de Bardena Blanca: 33\% cereal y 67\% de monte bajo. Observaciones a campo muestran en el Cantalar la presencia de dos grandes tipos de cárcavas permanentes, según posean o no un horizonte superficial de roca arenisca (Campo et al., 2007). Concretamente, a las cárcavas sin roca arenisca las identificamos con el adjetivo convencional, mientras que a su análoga, la calificamos como, de arenisca. Dentro del primer grupo (convencional) podemos distinguir otro tipo de cárcavas que se originan por la acción de un flujo subsuperficial (erosión por túnel). A este tercer grupo de cárcavas la calificamos como asociadas a túnel. A través del uso de fotografías áreas y de mediciones a campo (Fig. 10), se determinó que en las últimas décadas el promedio de 


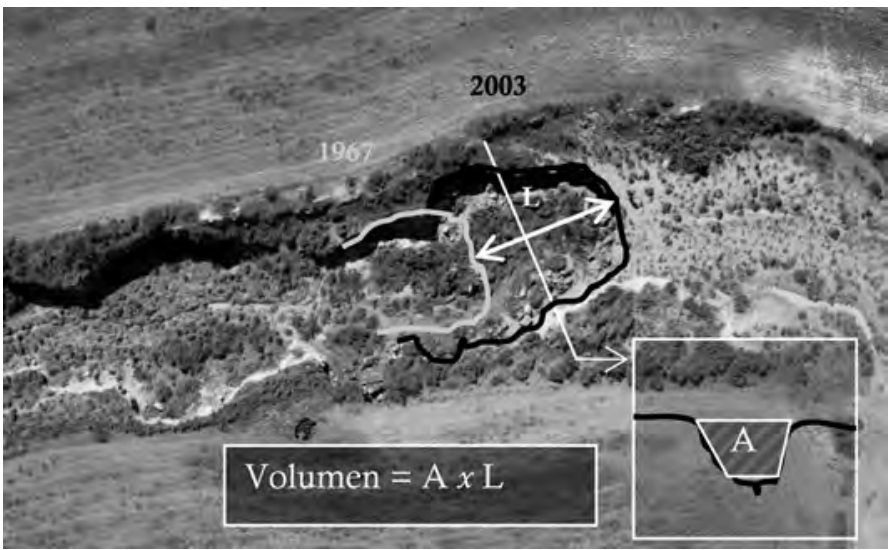

Figura 10. Fotografía aérea de una cárcava permanente mostrando el desplazamiento de su cabecera durante el período 1967 y 2003 en las Bardenas Reales de Navarra. Se esquematiza también la forma en que se estima el volumen erosionado. El ancho de la cabecera es de aproximadamente $6 \mathrm{~m}$

avance de cabecera de cárcava fue de unos 6.000 y $3.000 \mathrm{~kg} \mathrm{ha}^{-1}$ año $^{-1}$ para cárcavas convencionales y de arenisca, respectivamente (Tabla 1). Mientras que en las cárcavas asociadas a túnel la intensidad de erosión en cabecera fue muy superior, incluso en un orden de magnitud (alrededor de $94.000 \mathrm{~kg} \mathrm{ha}^{-1} \mathrm{año}^{-1}$ ) (Tabla 1). Por otro lado, se estableció, aunque sólo para cárcavas convencionales, una elevada correlación entre el avance (volumétrico) de cabecera con el área de aporte de la cárcava correspondiente (Fig. 11) (Campo et al., 2007). Sorprendentemente, no se encontró ninguna relación significativa entre este avance de cabecera con la pendiente del terreno, como sí fue el caso, como se recordará, en cárcavas efímeras (De Santisteban et al., 2006).

Tabla 1. Intensidad de retroceso de la cabecera para los diferentes tipos de cárcavas

\begin{tabular}{|c|c|c|c|c|c|}
\hline \multirow[t]{2}{*}{ Cabecera } & $\mathbf{m}^{3}$ año-1 & $\mathbf{m}^{3}$ año-1 & $m^{3}$ año-1 & $\mathrm{kg} \mathrm{m}^{-2 \dagger} \mathrm{año}^{-1}$ & $n^{\dagger \dagger}$ \\
\hline & 1967-1982 & $1982-2003$ & $1967-2003$ & $1967-2003$ & \\
\hline Arenisca & 0,52 & 0,37 & $0,43 \pm 0,29$ & 0,29 & 16 \\
\hline Túnel & 1,17 & 1,18 & $1,18 \pm 0,15$ & 9,36 & 3 \\
\hline Convencional & 1,26 & 0,92 & $1,04 \pm 0,55$ & 0,57 & 21 \\
\hline
\end{tabular}

$\dagger$ area $\left(\mathrm{m}^{2}\right)$ referida al área de contribución. Densidad aparente $=1500 \mathrm{~kg} / \mathrm{m}^{3} . \dagger \dagger \mathrm{n}$ : número total. 


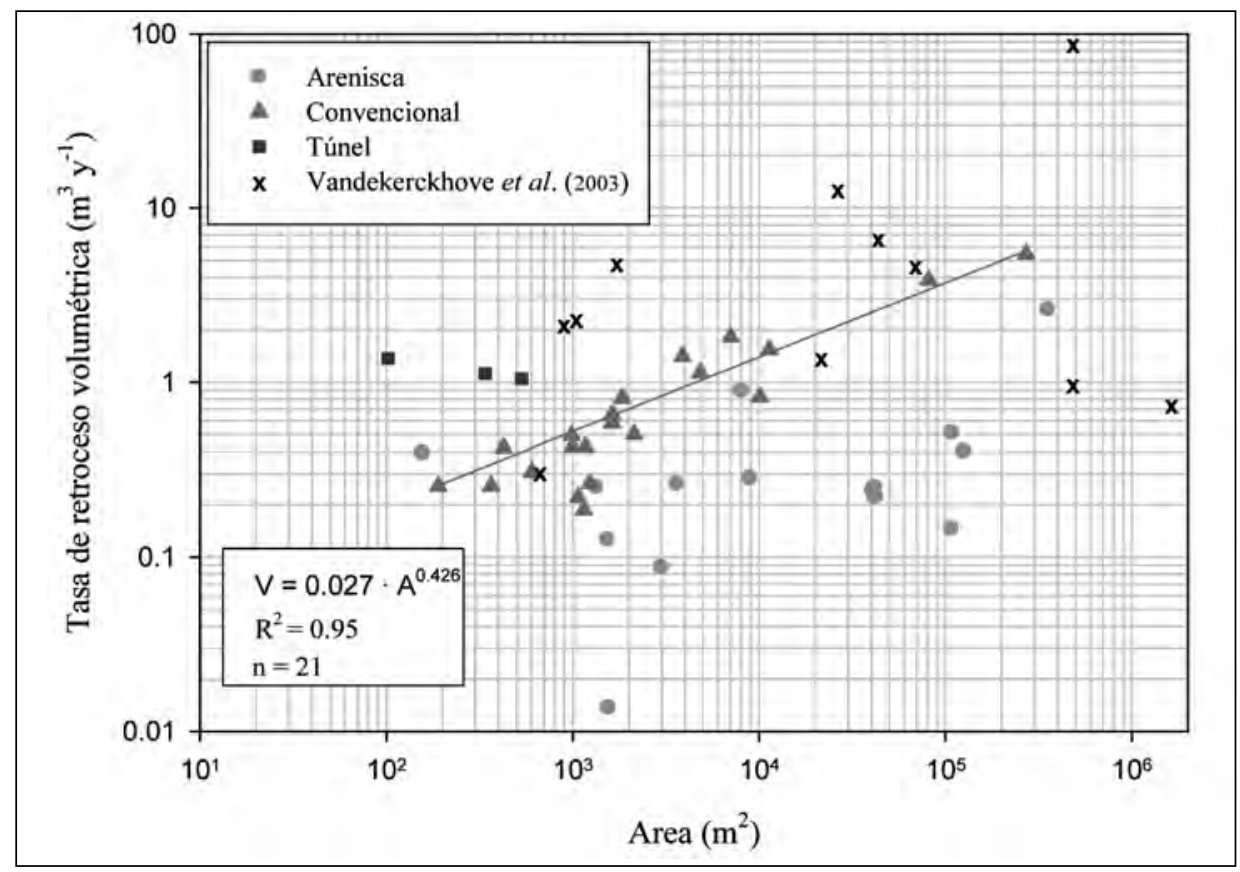

Figura 11. Relación estadística entre el área de contribución y la tasa de retroceso volumétrica para diferentes tipos de cabeceras de cárcavas

\section{Conclusiones}

Amplias zonas de Navarra se encuentran afectadas por erosión por flujos concentrados, superándose con frecuencia aún los más permisivos umbrales de tolerancia de pérdida de suelo. A pequeña y mediana escala (menos de una hectárea), el uso de la tierra y en particular el tipo de cultivo y su manejo, parecen jugar un papel esencial en el proceso erosivo. Por ejemplo, los viñedos requieren de mayor laboreo, y durante todo el año, que los cereales. De ahí que se observaron mayores pérdidas de suelo en zonas bajo viñedos que bajo cereales. Además, esta degradación del suelo es debida, principalmente, a la acción de cárcavas efímeras y en menor medida, a surcos. Por otro lado, si bien se registran lluvias erosivas durante todo el año, las mismas son más frecuentes e intensas durante el período invernal, momento en el cual el suelo se encuentra, además, más desprotegido y húmedo. Esto último explica el hecho de que las mayores pérdidas de suelo ocurran durante el invierno.

A nivel de cuenca, en cambio, la complejidad del terreno, propia de nuestra región, prevalece entre los factores condicionantes en la producción de sedimentos. Precisamente, en cuencas cerealistas, similares en características básicas como suelo, clima y geología, los registros de producción de sedimentos pueden ser muy diferentes entre sí, dependiendo de la forma general de la cuenca y de su relieve. De hecho, mientras en un tipo de cuenca analizada la producción anual de sedimentos fue muy baja, en otra aná- 
loga, la cantidad de los mismos fue varias veces superior. Esto último, debido a la intensa erosión por cárcavas efímeras observada en la primera de las cuencas, aunque sólo en algunas de sus subcuencas. En cuencas forestales los valores de pérdidas de suelo se ubican por debajo de los registrados en cuencas agrícolas, siempre y cuando se realice un correcto manejo de los bosques.

Una amplia región de Navarra, especialmente la meridional, está seriamente afectada por erosión bajo la forma de cárcavas permanentes. Las pérdidas de suelos son especialmente graves cuando la erosión por flujos concentrados superficiales se asocia a la erosión por túnel. En este último caso, las pérdidas de materiales pueden superar varias veces los umbrales de tolerancia que generalmente se aceptan.

\section{Referencias bibliográficas}

Alonso, C. (2007). Ephemeral gully erosion research: processes and modelling. En Progress in gully erosion research. (Casalí, J., Giménez, R. Eds.). Universidad Pública de Navarra, Dirección de Publicaciones, pp: 15-17, Pamplona.

BRICE, J.B. (1966). Erosion and deposition in the loess-mantled Great Plains, Medecine Creek drainage basin, Nebraska. U.S. Geological Survey Professional Paper 352H: 235-339.

CAmpo, M.A., ÁlaVAREZ-Mozos, J., CASAlí, J., GimÉNEZ, R. (2007). Effect of topography on retreat rate of different gully headcuts in bardenas reales (Navarre, Spain). En Progress in gully erosion research. (Casalí, J., Giménez, R. Eds.). Universidad Pública de Navarra, Dirección de Publicaciones, pp: 24-25, Pamplona.

CASAlí, J., LóPeZ, J.J., GIRÁldEZ, J.V. (1999). Ephemeral gully erosion in southern Navarra (Spain). Catena, 36 (1-2): 65-84.

Casalí, J., Loizu J., Campo, M.A., De Santisteban, L.M., Alvarez-Mozos, J. (2006). Accuracy of methods for field assessment of rill and ephemeral gully erosion. Catena, 67 (2): 128-138.

Casalí, J., Gastesi, R., Álvarez-Mozos, J., De Santisteban, L. M., Del Valle de Lersundi, J., Giménez, R., LarrañagA, A., GoÑi, M., CAMPO, M.A. (2008). Runoff, erosion, and water quality of agricultural watersheds in central Navarre (Spain). Agricultural Water Management, 95 (10): 1111-1128.

Casalí, J., Giménez, R., De Santisteban, L. Álvarez-Mozos, J., Mena, J., Del VALLE DE LERSUNDI, J. (2009). Determination of long-term erosion rates in vineyards of Navarre (Spain) using botanical benchmarks. Catena, 78 (1): 12-19.

De SANTiSTEBAn, L.M., CASAlí, J., LÓPEZ, J.J. (2006). Assessing soil erosion rates in cultivated areas of Navarre (Spain). Earth Surface Processes and Landforms, 31(4): 487-506. 
Desir, G., MARIN, C. (2007). Effects of slope processes and management in gullying. En Progress in gully erosion research. (Casalí, J., Giménez, R. Eds.). Universidad Pública de Navarra, Dirección de Publicaciones, pp: 38-39, Pamplona.

Donézar, M., Illarregui, M., Del VAl, J., Del VAlle de Lersundi, J. (1990a). Erosión actual en Navarra. Gobierno de Navarra. Ministerio de Comercio y Turismo.

Donézar, M., Illarregui, M., Del VAl, J., Del VAlle de LeRsundi, J. (1990b). Erosión potencial en Navarra. Gobierno de Navarra. Ministerio de Comercio y Turismo.

DunNE, T. (1990). Hydrology, mechanics, and geomorphic implications or erosion by subsurface flow. In: Groundwater Geomorphology: The Role of Subsurface Water in Earth-Surface Processes and Landforms. (Higgins, C.G., Coates, D.R., Eds.), Geological Society of America Special Paper, vol. 252. Boulder, Colorado.

Echeverría, M.T., Ibarra, P., Pérez-Cabello, F. (2007). Agricultural land use, piping and gullies activity in the Huerva lower valley (Saragossa, Spain). En Progress in gully erosion research. (Casalí, J., Giménez, R. Eds.). Universidad Pública de Navarra, Dirección de Publicaciones, pp: 44-45, Pamplona.

ElíAS, F., Ruíz, L. (1986). Caracterizaciín Agroclimaática de Navarra. Ministerio de Agricultura, Pesca, y Alimentación, Madrid.

FAULKNER, H. (2006). Piping hazard on collapsible and dispersive soils in Europe. En Soil erosion in Europe (Boardman, J., Poesen, J., Eds). pp: 537-562.

FOSTER, G.R. (1986). Understanding ephemeral gully erosion. Soil Conservation, vol. 2. National Academy of Science Press, Washington, DC,: 90-125.

GimÉNEZ, R., Govers, G. (2001). Interaction between bed roughness and flow hydraulics in eroding rills. Water Resources Research, 37 (3): 791-799.

GimÉnEZ, R., Planchón, O., SilverA, N., GOVERS, G. (2004). Longitudinal velocity patterns and bed morphology interaction in a rill. Earth Surface Processes and Landforms, 29(1): 105-114.

Gobierno DE NAVARRA, (1997). Mapa geológico de Navarra 1:200.000. Gobierno de Navarra, Departamento de Obras Públicas, Transportes y Comunicaciones, Pamplona.

GobIERNO DE NAVARRA, (2004). Mapa de cultivos y aprovechamientos de Navarra. Departamento de Agricultura, Ganadería y Alimentación. Secretaría Técnica. Sección de Evaluación de Recursos Agrarios. Pamplona.

Gordon, L.M., Bennett, S.J., Alonso, C.V., Bingner, R.B. (2007). Ephemeral gullies: to till or not to till? En Progress in gully erosion research (Casalí, J., Giménez, R. Eds.). Universidad Pública de Navarra, Dirección de Publicaciones, pp: 54-55, Pamplona. 
GOVERS, G. (1992). Relationship between discharge, velocity and flow area for rills eroding loose, non-layered materials. Earth Surface Processes and Landforms, 17: 515-528.

Govers, G., GimÉNEZ, R., VAN OOST, K. (2007). Implications of recent experimental findings for rill erosion modelling. En Progress in gully erosion research (Casalí, J., Giménez, R. Eds.). Universidad Pública de Navarra, Dirección de Publicaciones, pp: 56-57, Pamplona.

Hall, G.F., Logan, T.J., Young, K.K. (1985). Criteria for determining tolerable erosion rates. In Soil Erosion and Crop Productivity (Follett, R.F., Stewart, B.A, Eds). American Society of Agronomy, Crop Science Society of America, Soil Science Society of America: Madison, Wisconsin.

Hauge, C. (1977). Soil erosion definitions. California Geology, 30: 202-203.

HILlEL, D. (1998). Environmental soil physics. Academic Press, 771p.

HowARD, A.D. (2008). Badlands and Gullies. In: Geomorphology of Desert Environments (Parsons, A. J., Ed), 2nd ed., Chapman \& Hall, London.

HutChInSON, D.E, PRITCHARD, H.W. (1976). Resource conservation glossary. Journal of Soil and Water Conservation, 31: 1-63.

ICONA, 1988. Agresividad de la lluvia en España. Valores del factor R de la Ecuación Universal de Perdidas de Suelo. Servicio de publicaciones del MAPA. Madrid

IMESON, A.C., KWAAD, F.J.P.M. (1980). Gully types and gully prediction. KNAG Geografisch Tijdschrift XIV (5): 430-441.

Morgan, R.P.C. (2005). Soil Erosion and Conservation. Blackwell Publishing. Third Edition. 304 p.

Nachtergaele, J., Poesen, J. (1999). Assessment of soil losses by ephemeral gully erosion using high-altitude (stereo) aerial photographs. Earth Surface Processes and Landforms, 24 (8): 693-706.

Poesen, J.W.A., Hooke, J.M. (1997). Erosion, flooding and channel management in Mediterranean environments of southern Europe. Progress in Physical Geography, 21 (2): 157-199.

Poesen, J., Valentin, C. (2003). Gully Erosion and Global Change. Catena, 50 (2-4): 87-564.

Poesen, J., Nachtergaele, J., Verstraeten, G., Valentin, C. (2003). Gully erosion and environmental change: Importance and research needs. Catena, 50 (2-4): 91-133.

Poesen, J., Vanwalleghem, T., De Vente, J., Knapen, A., Verstraeten, G. MartínezCasasnovas, J.A. (2006). Gully Erosion in Europe. En Soil erosion in Europe. (Boardman, J., Poesen, J., Eds.). pp: 479-488. 
RAMOS, M.C., MARTínEZ-CASASNOVAS, J.A. (2004). Nutrient losses from a vineyard soil in Northeastern Spain caused by an extraordinary rainfall event. Catena, 55(1): 79-90.

Sancho, C., Benito, G., Gutiérrez, M. (1991). Agujas de erosión y perfiladores microtopográficos. Cuadernos Técnicos de la Sociedad Española de Geomorfología, 2. Geoforma Ediciones. Logroño.

ScHumm, S.A. (1956). Evolution of drainage systems and slopes in badlands at Perth Amboy, New jersey. Bulletin of the Geological Society of America, 67, 597-646.

SMITH, L.M. (1993). Investigation of ephemeral gullies in loessial soils in Mississippi. Technical Report GL-93-11. US Army Corps of Engineers. Vicksburg.

SoIL SCIENCE SocIETY OF AMERICA. (2001). Glossary of Soil Science Terms. Soil Science Society of America, Madison, WI, http://www.soils.org/sssagloss/.

Solé Benet, A. (2006). Soil Erosion in Spain. En Soil erosion in Europe. (Boardman, J., Poesen, J. Eds.). pp: 311-346.

TAKken, I., Govers, G., CiesiolKa, C.A.A., Silburn, D.M., LoCH, R.J. (1998). Factors influencing the velocity-discharge relationship in rills. Proceedings of the international symposium on modelling soil erosion, sediment transport and closely related hydrological processes, Vienna, 1998. IAHS Publication $\mathrm{N}^{\circ} 249$ : 63-70.

Wilson, G.V., Cullum, R.F., RÖMKEnS, M.J.M. (2008). Ephemeral gully erosion by preferential flow through a discontinuous soil-pipe. Catena, 73(1): 98-106. 